\title{
A mixed methods contribution analysis of UK students' unions' internal communications response to addressing staff motivation during the Covid-19 pandemic
}

\author{
Matthew Kitching*
}

doi: http://dx.doi.org/10.18543/tjhe-9(1)-2021pp207-237

Received: 14 September 2021

Accepted: 27 October 2021

\begin{abstract}
This macro-level, mixed methods contribution analysis evaluates the influence of students' unions internal communication response to the Covid-19 pandemic on staff motivation. Recognising the role individual interpretation and perception play in the receipt of such messages, this paper seeks to understand which motivating factors union managers sought to address through their communications, whether these efforts were recognised by staff and whether there is evidence they may have helped to alleviate employee concerns. The evaluation findings will be of interest to student union managers and professionals looking to enhance communications and improve employee motivation.
\end{abstract}

Keywords: Students' Unions; Covid-19 pandemic; mixed methods; Contribution Analysis; internal communications; motivation.

\section{Introduction}

Since its emergence in early 2020, Covid-19 has wreaked havoc with higher education in the United Kingdom (UK). The second half of the 2019/20 academic year was thrown into disarray with classes suspended, campuses closed and the cessation of extra-curricular activities. The ensuing rush to enable online delivery was addressed with mixed success across the

* Matthew Kitching (m.kitching1@lancaster.ac.uk) is Deputy Chief Executive Officer of the Students' Union at Buckinghamshire New University (United Kingdom-UK). Simultaneously, Matthew is completing his MBA in the Edinburgh Business School at HeriotWatt University and undertaking his $\mathrm{PhD}$ in Higher Education at Lancaster University (UK). His research focusses on projects concerning student unions, student leadership and engagement, as well as work on quality assurance, in particular student involvement in international QA.

More information about the author is available at the end of this article. 
sector, as a report produced by the Quality Assurance Agency (QAA) highlighted. Where this transition worked well it largely reflected providers' starting positions. In instances where institutions were already delivering online programmes and/or had high levels of digital literacy among their communities, it proved easier. ${ }^{1}$ Consequently, the summer brought a welcome reprieve for staff and students alike.

Yet, that holiday season provided little respite for a Government beset with scandals over secondary and A-level examinations. ${ }^{2}$ It is perhaps little wonder therefore that they failed, in the eyes of many higher education institutions and commentators, to provide satisfactory guidance for reopening campuses in the autumn. This against a backdrop of concern from stakeholders, including the independent SAGE group. ${ }^{3}$ University College Union (UCU) and the National Union of Students (NUS) about the risks posed by re-opening campuses from August 2020.,5

Those concerns proved legitimate, as no sooner had universities and colleges welcomed students back onto site and into halls of residence than a picture emerged of alarming transmission rates in large university cities and institutions including Glasgow, Manchester, Newcastle, Nottingham and Liverpool. Media coverage of these issues at the time was prominent, as well as that which focused on a growing level of concern surrounding students' mental health as they were confined to their halls and homes and struggled to make virtual connections with their peers and lecturers. ${ }^{6}$

${ }^{1}$ QAA, "How UK Higher Education Providers Managed the Shift to Digital Delivery During the Covid-19 Pandemic," (2020), https://www.qaa.ac.uk/docs/qaa/guidance/how-ukhigher-education-providers-managed-the-shift-to-digital-delivery-during-the-covid-19pandemic.pdf.

2 Tola Onanuga, "The Government's Disastrous a-Level Scandal Reveals Its Contempt for the Working Class," Prospect Magazine, (2020), https://www prospectmagazine.co.uk/ politics/government-a-levels-grades-uk-explained-downgraded-gavin-williamson.

${ }^{3}$ The Independent Scientific Advisory Group for Emergencies formed in the early stage of the pandemic as an alternative scientific voice to the Government's Scientific Advisory Group for Emergencies (SAGE). https://www .independentsage.org/

${ }^{4}$ David King, "Independent Sage Response to Sage "Principles for Managing SarsCov-2 Transmission Associated with Higher Education," Independent SAGE, (2020), https:// www.independentsage.org/wp-content/uploads/2020/09/iSAGE-response-to-S AGE-HEFINAL-09-09-2020.pdf.

${ }^{5}$ UCU, "Universities Must Not Become the Care Homes of a Covid Second Wave," @ иси, (2020), https://www.ucu.org.uk/article/10964/Universities-must-not-become-the-carehomes-of-a-Covid-second-wave.

${ }^{6}$ Tom Gillespie, “Coronavirus: Students Say Starting University During the Pandemic Is Impacting Their Mental Health”, Sky News, (2020), https://news.sky.com/story/coronavirusstudents-say-starting-university-during-the-pandemic-is-impacting-their-mental-health-12081273. 
There are over 600 students' unions in the UK and the overwhelming majority were as exposed to the turmoil brought about by the pandemic as their institutions. While the form, size and services offered by these unions varies widely, many organise a combination of social, cultural, representative and campaigning functions, which they attempted to adapt in order to transition them wholly or partly online. In addition to shifting the mode of delivery for this activity into a virtual space they had to oversee the move to home working for their multi-disciplinary units. This forced migration arguably exacerbated existing challenges associated with building effective teams, and working collaboratively, in organisations where responsibilities range from student sport to advice and from representation to the operation of licensed premises. The demand for some of these services (advice and representation) heightened during the pandemic whereas others (sport and bars) have, at points, come to a complete halt. Add to this the same challenges faced by other organisations when it comes to social interaction, the provision of adequate technology and resources for home-working, as well as staff concerns over finance, housing and mental health and it becomes clear that students' union staff and their management teams have had much to contend with in the past year and a half.

The object of this evaluation comprises the full gamut of communications received by union employees during the initial stages of what, at the time of writing, is an ongoing pandemic, from all-staff, departmental and individual emails to social media communications and online and face-to-face meetings. Specifically, the focus of the evaluation is on understanding the link between those communications and staff motivation. The fieldwork for this evaluation took place between September and November 2020, a point in time when a significant number of unions were operating under various forms of local lockdown and the spectre of further national restrictions was growing. This was followed by a 'third lockdown' and while the impact of the vaccination programme appears to have blunted (though not entirely removed) the prospect of further lockdowns in academic year 2021/22, the findings of this research remain important for academics and practitioners. Students' unions may yet find that they are required to pivot back to online activity if the National Health Service becomes overwhelmed; consequently, there remains a critical imperative for students' unions to do all they can to improve their communications. Additionally, organisations are reporting their intent to retain the few positives brought about by the pandemic, including hybrid working. ${ }^{7}$

Mark Johanson, "Hybrid Work: What the Office Could Look Like Now," BBC, (2021), https://www.bbc.com/worklife/article/20210713-hybrid-work-what-the-office-could-looklike-now. 
In order to place themselves in the best possible position, both in case of a future lockdown and to maximise the benefits of hybrid working, unions need to understand how effective their strategies have been to date and how their staff have been affected. This evaluation serves to address that need and help unions to adapt and improve their response, and associated communications, during the next phase of the crisis. To assist with that, unions who participated in the evaluation and secured ten or more respondents were offered optional data reports to support their internal reflection and strategic planning for possible further lockdowns and extended home working.

In terms of the paper's structure, it will first discuss the operative evaluative approach, Contribution Analysis, including the epistemological basis for its selection, as well as its practical utility. Following this, comes a brief overview of Maslow's Hierarchy of Needs, which provides the foundation for the postulated theory of change; a required element for Contribution Analysis. A methods section will then explain how these theoretical and evaluative constructs were integrated, as well as addressing survey design and piloting, access and recruitment and ethical considerations. The sections of the paper that follow will provide an exposition of the evaluation's findings and their apparent implications for practice, as well as some reflections on the limitations of my work and future directions for further research and evaluation.

\section{Methodology}

\section{II.1. An interpretivist approach to contribution analysis}

Mayne's Contribution Analysis follows a six step process in order to "explore attribution through assessing the contribution a programme is making to observed results" ${ }^{8}$ In line with the evaluation object and focus outlined in the Introduction, unions' internal communications represent the programme being assessed and staff motivation forms the observed results. In this instance, the contribution that the programme makes was assessed through a survey of students' union staff, which combined quantitative and qualitative data on their motivation and experience before and during the Covid-19 pandemic. Specifically, the following questions are addressed:

1. What motivational factors had staff been concerned about between the start of the pandemic in the UK and the fieldwork period?

8 John Mayne, “Contribution Analysis: Coming of Age?,” Evaluation 18, no. 3 (2012), https://journals.sagepub.com/doi/abs/10.1177/1356389012451663. 
2. To what extent did union managers seek to address these concerns through their communications, and how?

3. Were these efforts recognised by staff and is there evidence to draw on that communications may have helped to alleviate employee concerns?

Contribution Analysis is best suited to this evaluation for four primary reasons:

1) It is conducive with an interpretivist approach: for every member of staff who received a communication during the pandemic its influence on their motivation is likely to have varied, depending on a range of factors including their pre-existing motivation and their personal circumstances; for example, in relation to their finances, health and/or ambition. Therefore, in order to understand the influence that communications have on staff we must seek to understand more about them as individuals. Contribution Analysis enables such an approach, which on this occasion has been achieved, in part, by including questions in the survey device on pre-pandemic opinions across a range of factors and on the pandemic's financial impact on individuals.

2) It takes account of complexity: Mayne acknowledges the existence of complex 'causal packages', whereby interventions do not act alone. Instead, a combination of causal factors is likely to be needed in order to bring about the desired outcomes. ${ }^{9}$ Despite this, Contribution Analysis allows you to foreground certain factors and still make contribution claims, providing you acknowledge the existence and potential influence of the remaining factors. Here, the interpretivist model adopted in this evaluation is aligned with my theory of change, outlined in full in the next section, and the decision to foreground staff perception at the expense of gathering data which might have provided evidence about a particular intervention, but which would not have allowed me to make inferences about how it was perceived by staff. This formed the basis of inclusion and exclusion criteria for the evaluation. Excluded was any primary analysis of individual programme interventions or communications. Conversely, inclusion criteria centred on data which enabled me to understand staff perceptions of those interventions and the communications in which they were outlined.

3) It is not prescriptive about the need to determine definitive causal attribution: Mayne would describe an attempt to understand how a 
particular decision or individual communication influenced staff motivation as a "traditional causality" sort of question. Like Mayne, I recognise the existence of causal packages and that without taking the full range of factors that may have influenced staff motivation into account it is not possible to robustly answer a question of this type. However, Mayne also identifies what he calls "managerial questions" which include whether "it is reasonable to conclude that the programme has made a difference to the problem". By identifying the strategic intention of managers in developing their communication strategies, gathering data on how these communications have been perceived by staff and observing differences in motivation across range of factors before and during the pandemic, it becomes reasonable to conclude whether manager's intentions have been realised; or whether communications have had a negative influence on staff motivation.

4) It permits subjective determinations about the required level of proof: Mayne is clear that the level of proof required is a decision for the evaluator, based on what they intend to do with the findings. ${ }^{10}$ In this case, where I have agreed to provide participating unions with data reports, they will be triangulating my findings against other data sources and their own understanding of their local context. This has also informed the decisions that I have taken about sample size.

Added to these reasons, Contribution Analysis is designed to be an iterative approach. This means initial data gathering and analysis can be carried out in a relatively short timeframe, especially important given the ongoing nature of the pandemic and the need for union managers, who are seeking improvement rather than perfection, to apply any learning quickly. Alternative approaches to evaluation were considered, in particular Realist Evaluation, however a determination was made that the human and financial resources required to conduct such an evaluation were not available, but that a similar study using Contribution Analysis could be carried out, at scale, that would be equally robust, credible and have comparable utility for practitioners in the field. The next section of this paper outlines the theory of change used in the evaluation which, as has already been stated, is something that Mayne considers an integral part of Contribution Analysis.

${ }^{10}$ John Mayne, “Contribution Analysis: An Approach to Exploring Cause and Effect,” (2008), https://www.betterevaluation.org/sites/default/files/ILAC_Brief16_Contribution_Analysis.pdf. 


\section{II.2. Theory of change}

My theory of change (see Figure. 2) is predicated on the basis that managers identify concerns that are likely to effect staff motivation, that they then identify existing and/or new interventions to address these concerns and communicate them to their employees, who process that information and, where this is done effectively, it has a positive impact on motivation. The theory was also constructed based on a hypothesis, having viewed emerging communications from several students' unions, that Maslow's hierarchy of needs was implicitly forming the basis of unions' communications strategies. ${ }^{11}$ Consequently, the survey device was built to align sections against Maslow's tiers, which also allowed his theory to be used as an analytical tool when interrogating the data.

Maslow's theoretical framework for individual personality development and motivation operates from an interpretivist position, which recognises the centrality of individual wants and needs in relation to motivation. The basic premise being that what someone wants depends on what they already have. ${ }^{12}$ Maslow argues that, broadly speaking, needs at the base of his hierarchy (see Figure. 1) have to be satisfied before individuals become concerned with the next tier. In the context of this evaluation we look to understand how internal communication contributes to this progression.

It should be noted that there are challenges to using Maslow's theory in the workplace. Firstly, as noted by Mullins ${ }^{13}$, it was not originally developed for such settings, and factors in an employee's personal life also contribute to their overall motivation. This paper's findings describe results which demonstrate a linear picture of escalating concerns through the hierarchy, but caution must be exercised here. Maslow himself recognised that this is not always the case and individuals' personal context determines their position in relation to the various tiers and that for some the order of need will be different. Notwithstanding the caution that needs to be exercised, the theory provides a credible and effective prism through which to analyse staff experience and offers explanatory power in relation to my data findings.

However, understanding the different factors that influence motivation is insufficient. This might enable an organisation to plan an intervention; but, unless they can communicate that effectively to their staff, who in turn attribute the same significance to it, it is unlikely to be successful. For

\footnotetext{
11 A. H. Maslow, “A Theory of Human Motivation,” Psychological Review 50, no. 4 (1943).

${ }^{12}$ Laurie J. Mullins, Management and Organisational Behaviour (Welwyn Garden City, UNITED KINGDOM: Pearson Education UK, 2013).

${ }^{13}$ Ibid.
} 


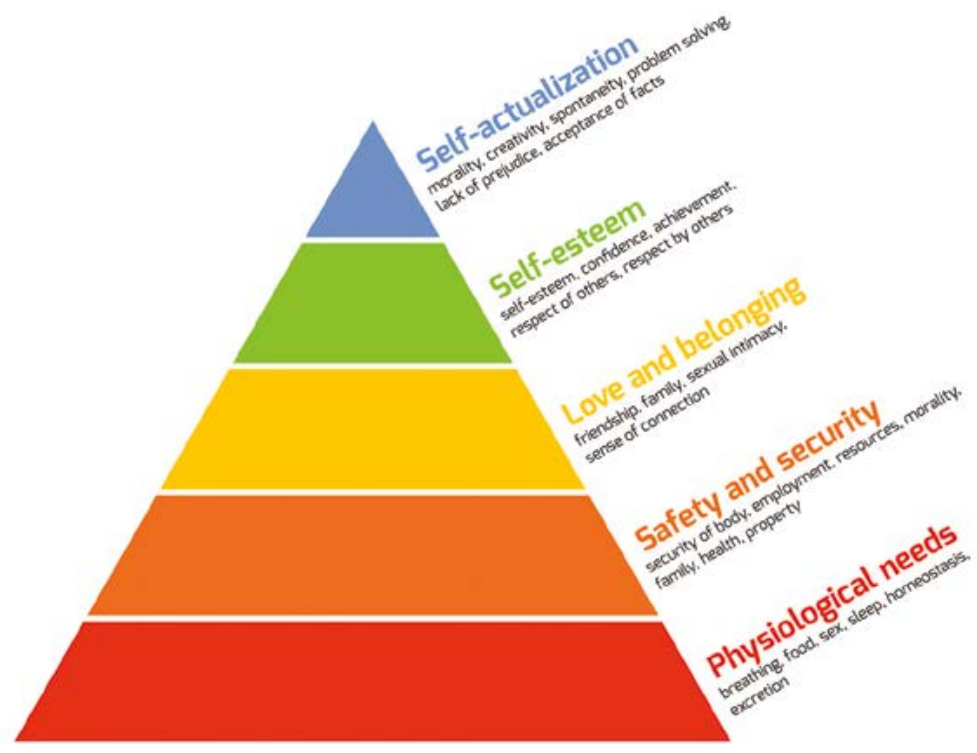

Figure 1

Maslow's hierarchy of needs

example, it isn't enough to develop an excellent reward scheme for staff, they have to be told it exists, why and how it will benefit them and what they need to do in order to benefit. This also has to be done in ways that they can understand, and managers need mechanisms in place to receive feedback that allow them to assess that understanding has occurred.

In her work, Lyn Smith brings together the three essential strands of this evaluation in a compelling fashion: namely, Maslow's Hierarchy of Needs, the role of the individual and internal communication. ${ }^{14}$ Smith, quoting a senior communications consultant, addresses the utility of Maslow's theory for the important task of focusing on the individual and not purely on systems; because, as she puts it: "people are unpredictable, rational and emotional'. Smith's argument that "taking the time to understand the motivations of individuals rather than treating them as an amorphous group should pay dividends for the internal communicator". These observations point to the complexity required for successful communications. Managers need to

${ }^{14}$ Lyn Smith, "Part 1: Setting the Scene - Chapter 04: Theories into Practice," 2nd ed. (London: Kogan Page Ltd, 2008). 


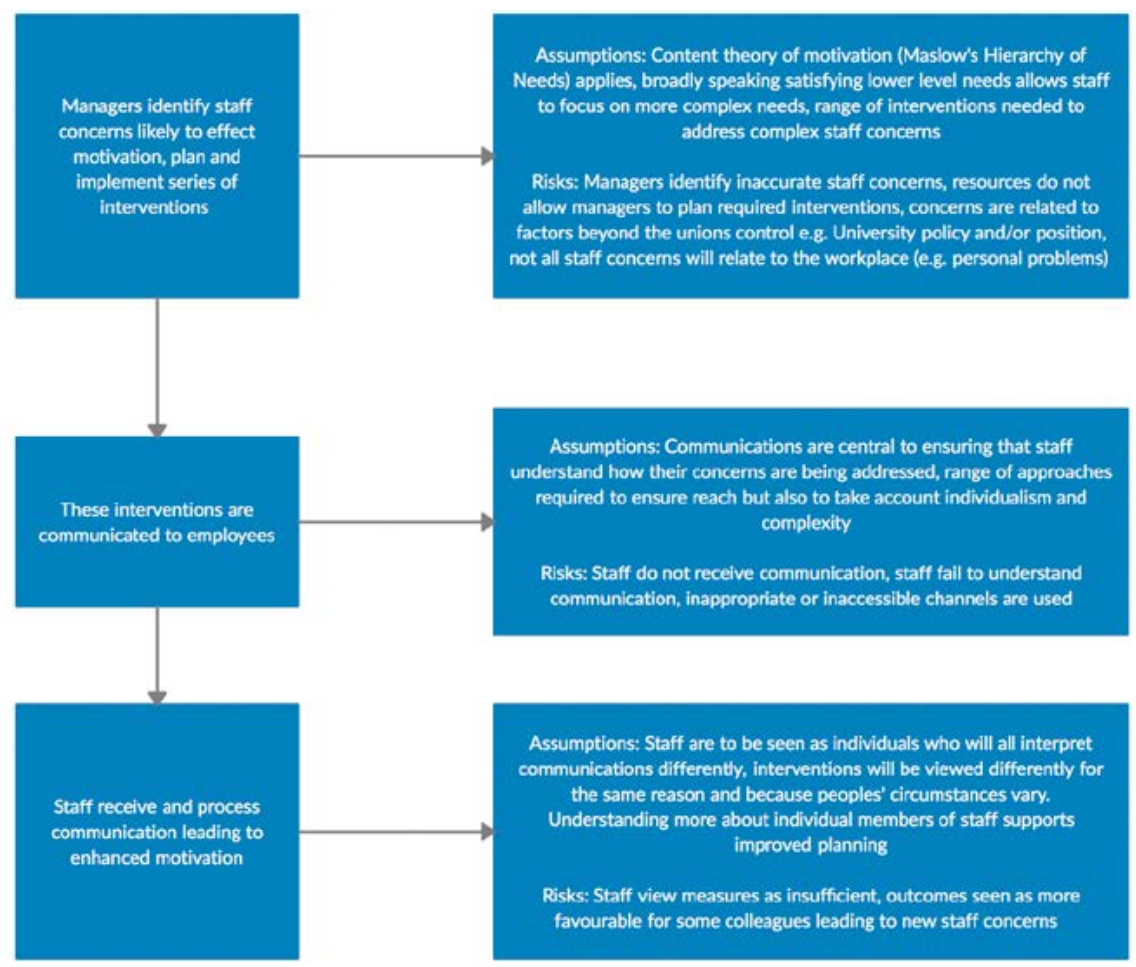

Figure 2

Theory of change for enhancing staff motivation in students' Unions

understand the motivations of individual staff members, which requires not just tailored communications but, ideally, interventions. This is fraught with risk; managers may identify inaccurate concerns, insufficient resources may exist to provide the full range of interventions that are required, messages may be communicated ineffectively, inappropriately or inaccessibly to certain groups or individuals. Figure 2 shows these, and other risks integrated into the theory of change, together with its fundamental assumptions.

\section{II.3. Survey design}

In order to operationalise the theory of change within the evaluation, survey questions were positioned against the five levels of human need that Maslow identifies in his research: physiological, safety, belongingness, 
esteem and self-actualisation. These needs were mapped to the operating context under which students' union staff were working. For instance, belongingness was mapped to reduced opportunities for socialisation and collaborative working, esteem to reward and recognition arrangements and self-actualisation to career progression and the provision of professional development opportunities. Physiological and safety needs were largely combined and mapped to granular financial concerns, including debt and difficulty paying mortgage and rent.

Having mapped Maslow's hierarchy to issues facing students' union staff during the pandemic, some of the motivational factors I used during the evaluation required me to develop a working definition for participants. Capability was taken to mean the broad range of factors which collectively enable staff to achieve in their role. This includes the provision of appropriate technology and working spaces. It also includes appropriate induction arrangements, suitable supervision and support from colleagues, as well as the provision of clear instructions, duties and expectations. Just as I produced a broad working definition for capability, I informed participants that belongingness was assigned a similarly broad definition in this evaluation. It was taken to mean the extent to which staff feel part of a team and have a pride and attachment in working for the Union. It also concerns their connectedness with colleagues through opportunities for socialisation and collaboration.

The survey questions were piloted with two former colleagues, who are experienced practitioners in the field, and feedback led to minor adjustments. Changes included an opportunity to provide any further comments at the end of the survey and the inclusion of additional communication mechanisms that unions may have used. None of the feedback from the pilot data was included in the final analysis.

\section{II.4. Sampling, access, and recruitment}

As highlighted in the Introduction, there are over 600 students' unions in the UK. Yet, little scholarly attention has been paid to students' unions thus far; consequently, research looking into the scale and experiences of the students' union workforce across the UK is patchy and inconsistent and there is little comprehensive data about the number of staff working in the field..$^{15}$

${ }^{15}$ Mike Day and Jim Dickinson, "David Versus Goliath: The Past, Present and Future of Students' Unions in the UK," Higher Education Policy Institute, (2018), https://www.hepi. ac.uk/2018/09/06/david-versus-goliath-past-present-future-students-unions-uk-2/. 
For instance, the annual SU Survey carried out between NUS and senior sector staff does not include an overall headcount. Similar research, such as the National Employee Engagement Survey, suffers from consistently low response rates. The absence of comprehensive descriptive research and data presented a problem for sampling. In order to approximate the overall population, the significant variation in staff headcount across different unions was considered. The construct of the majority of students' unions operating across Further Education and within private providers is markedly different to equivalent unions operating in, historically publicly funded, Higher Education institutions. Professional staff support structures in the former often do not exist or they are less developed. This evaluation does not seek to draw findings that can be generalised to the former group. For that reason, I use, as a baseline, the 121 higher education institutions listed in the Guardian universities league table. The sampling strategy assumes a conservative estimated average of 30 staff per organisation across these unions, producing a total population of 3630 .

The significant qualitative data generated by the survey provides some latitude for a small overall sample, in that thematic analysis of this rich seam of data enables me to affirm, contest or offer alternative hypotheses to those developed from the quantitative data alone. A further mitigation against the need for a higher sample is the relative homogeneity of the population, all staff, working as they do, in one profession, student unionism. On this basis, the following equation was used to determine the sample size necessary for $95 \%$ confidence, .5 standard deviation and a margin of error of $+/-8 \%$ :

$$
\frac{\left((1.96)^{2} \times .5(.5)\right)}{(.8)^{2}}=145
$$

Having determined the necessary sample size a random sampling strategy was employed with an open call to participants advertised across established staff networks on Facebook Workplace and LinkedIn. I also attended a senior staff network meeting, organised by NUS, to promote the research. To act as an incentive and assist with recruitment, as indicated above, a further feature of the evaluation is that unions securing ten or more respondents were offered optional data reports to support their internal reflection and strategic planning for possible further lockdowns and extended home working. This overall approach resulted in a total of 151 staff from 35 different students' unions participating in the evaluation, with 5 of those organisations electing to request data reports. Figure 3 shows the breakdown by role of staff who participated in the survey. 


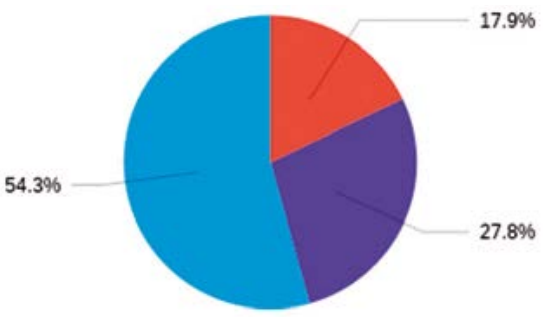

Senior Manager (responsible for helping to shape internal communications during Covid-19)

Middle Manager (recipient of internal communications but also responsible for cascading internal

communications during Covid-19)

Staff (reciplent of internal communications during Covid-19)

Figure 3

Role of students' union staff

\section{II.5. Data analysis and confidence levels}

This is a mixed-methods study and equal weight was given during the analysis to qualitative and quantitative analysis. The analytical approach employed in this evaluation used univariate and bivariate analysis, including Z-tests, to present quantitative data and examine relationships between variables. This data analysis has been used to drive qualitative thematic analysis of the substantial open text responses throughout the survey. For instance, data demonstrating a reduced sense of belongingness among furloughed staff has informed analysis of qualitative data concerned with action unions can take to address this deficiency. This, in turn, has instructed my deployment of quotes within my findings; whereby, I employ an illustrative presentational methodology, with those selected reflective of a larger number of similar qualitative responses from the data set.

Mayne discusses the need to determine the level of confidence required that the programme, in this instance unions' internal communications, has made a difference to the problem. ${ }^{16}$ This can vary depending on a range of factors including 1) what will be done with the results and 2) what decisions will be taken based on the findings. A determination has been made in this evaluation that a relatively low burden of proof is acceptable. Given one output from the evaluation has been a series of reports constructed for

${ }^{16}$ John Mayne, “Contribution Analysis: Coming of Age?,” Evaluation 18, no. 3, (2012), https://journals.sagepub.com/doi/abs/10.1177/1356389012451663. 
individual unions who participated. These organisations are able to contextualise the data and findings they were supplied with, based on the action and specific interventions that they know themselves to have implemented in their unions, together with other data and intelligence available to these organisations. The establishment of a survey device also allows the evaluation to be replicated in future studies to affirm or contest the findings presented in this paper.

\section{II.6. Ethical considerations}

From an ethical perspective, evaluating employees' experiences during the pandemic and their perception of internal communications could lead to highly sensitive discussions about individuals' finances, including debt, volatility in their housing situation, domestic violence and experiences of grief and distress due to family bereavement, illness and separation. In relation to unions, it is equally conceivable that dialogue could include confidential and sensitive information about an organisations' finances and viability, including the likelihood of redundancies. These considerations combined with my position as a senior staff member within the student movement, where I am known to a relatively wide range of staff and unions, influenced my selection of methods. I determined that interviews carried out within this context posed potential problems, such as a reluctance among participants to discuss personal finances, organisational viability and other sensitive information. Electing to use a survey, with a substantial qualitative element meant that participants could retain anonymity while still providing detailed, rich data about their experience and circumstances. Ethical approval was sought and received from the Department for Educational Research at Lancaster University.

\section{Findings}

\section{III.1. Staff concerns and the senior management response}

Table 1 illustrates a linear escalation through Maslow's hierarchy, with staff most concerned about those issues at the base of the hierarchy. The destabilising effect of the pandemic on organisations means the ensuing alarm about personal job security, which maps to the physiological and safety tiers, is the second most pronounced concern among respondents $(65.25 \%)$. Concerns about reduced opportunities for socialization (69.50\%), which map to Maslow's concept of belongingness, were more acute than those of job security. Interestingly however, preliminary results from this study, analysed 
at an earlier stage in the pandemic found job security was the most significant concern among staff. This serves to reinforce progress through Maslow's hierarchy, in that as initial fears of job security reduce slightly, the longer the crisis extends, the more staff become concerned about issues of belongingness.

These concerns were followed by those centred on arrangements for reward and recognition $(39.01 \%)$ and how staff members' value to the team is perceived $(35.46 \%)$, both of which correspond with the tier related to esteem needs. Finally, respondents were least exercised by career and development issues (34.04\%) which, again, supports Maslow's theory that you are more likely to become motivated by those factors at the upper tiers of the hierarchy once those underneath start to become satisfied.

The number of staff citing capability issues as a concern (51.06\%) could be viewed as an anomaly if you view access to appropriate equipment and support as being essential components to 'achieve one's potential' and thereby linked to Maslow's highest tier. However, the data here reflects the essential role that equipment, suitable home-working space and the provision of accessible support and supervision play at all stages of the hierarchy; they are fundamental enablers. Without these things in place the person is potentially unable to connect with colleagues, their work is inhibited and their contribution less likely to be acknowledged, in turn this makes them more susceptible to redundancy, as poor impressions about their contribution begin to form. Data on staff concerns alone appears to show that Maslow's Hierarchy of Needs has promise as a model understanding the motivation of students' union staff throughout the pandemic.

\section{Table 1}

Which of the following have you been personally concerned with during the Covid-19 Pandemic?

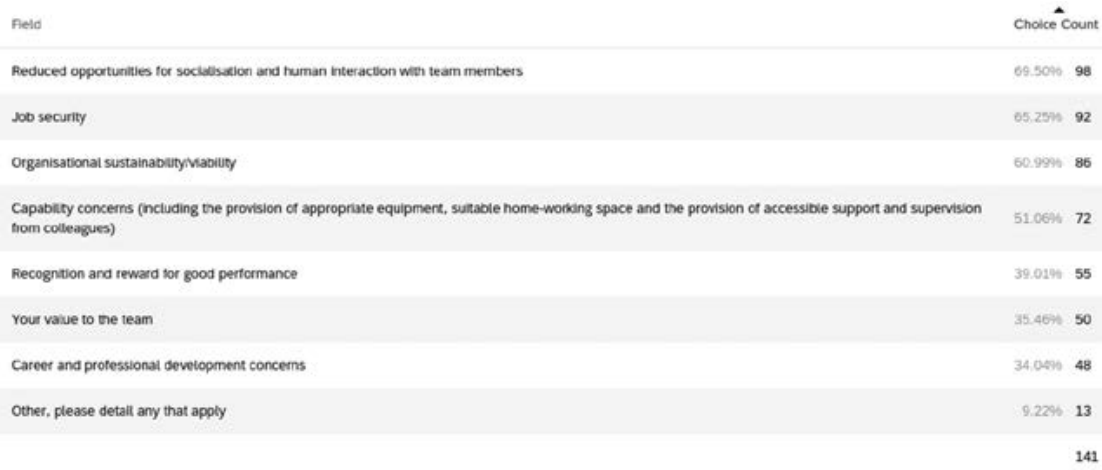




\section{Table 2}

Which of the following potential staff concerns did senior managers seek to address when constructing internal communications?

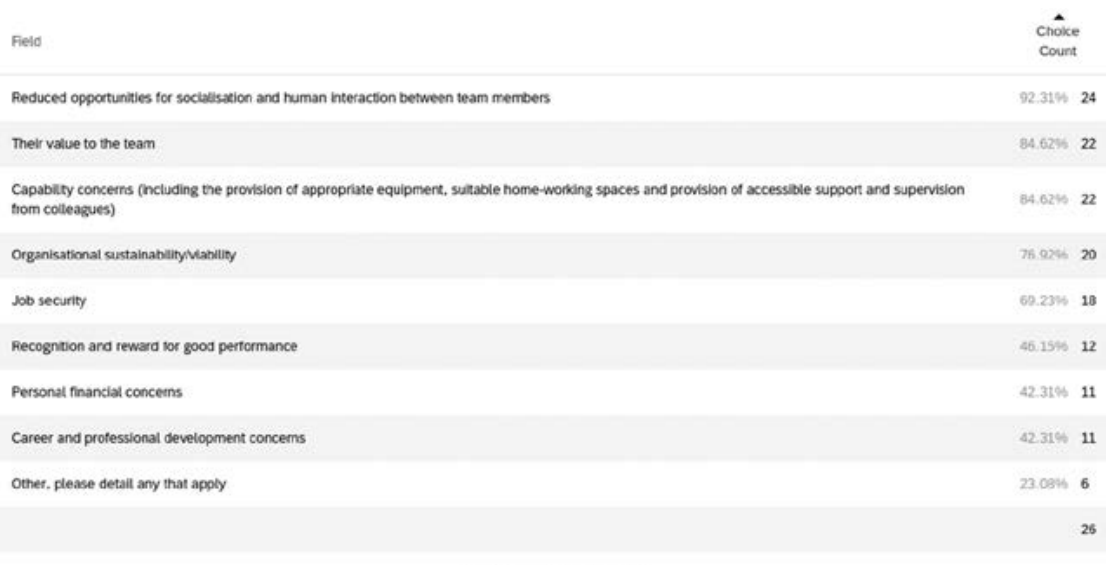

Showing rows $1-10$ of 10

Having established a more detailed understanding of staff concerns it is important to consider these in the context of senior managers' strategies when composing internal communications. Several significant observations are evident from Table 2; firstly, the emphasis senior managers placed on the different staff concerns does not entirely align with those of their staff. Despite job security being the biggest preoccupation of their staff, only $69.23 \%$ of senior managers believed their union sought to alleviate concerns in this area. Due to uncertainty this may have been harder to accomplish; however, only one senior manager referenced any discussion or consideration about redundancies having taken place. It therefore appears to be a reasonable assumption that unions could have offered assurances, at least for the shortterm. A greater number of senior managers believed that communications included positive statements about organisational sustainability and viability (76.92\%). That managers considered themselves more able to provide reassurance on an organisational rather than individual level is conceivably due to the more certain short-term positions and the fact that as their ongoing viability is intrinsically linked to the fortunes of their 'parent' universities, without direct reassurances from those institutions, managers arguably viewed themselves as constrained and less able to offer even short-term reassurance to their employees about their individual positions.

Another interesting observation from this data is that under half the managers taking part in the survey $(46.15 \%)$ consider that their communications 
included content designed to focus on reward and recognition. Although this was only a concern for $39.01 \%$ of staff, it provides one possible explanation for the volume of staff comments, discussed later, indicating they would have liked their efforts during a difficult phase of the pandemic to be acknowledged.

\section{III.2. Financial concerns, furlough, and job security}

Only $29.58 \%$ of respondents reported having experienced financial difficulties or concerns during the pandemic. While unions would want to avoid any of their staff encountering problems in this area, the fact this has been restricted to less than a third of the workforce is perhaps better than could have been expected. In fact, a closer inspection of these concerns (see Table 3) demonstrates that while $90 \%$ of those concerned about their finances reported suffering from anxiety, far fewer experienced actual problems with paying bills and/or debt. This is likely testament to the slightly protected short-term position of higher education, while the medium term forecast might well look grim, in-year losses were more modest, certainly in comparison to other sectors, and furlough prevented any large-scale redundancies. ${ }^{17,18}$

\section{Table 3}

Which of the following financial difficulties have you encountered?

\begin{tabular}{|c|c|}
\hline Fiedo & $\begin{array}{l}\text { Choike } \\
\text { Count }\end{array}$ \\
\hline Anciety about potential mancial probiems & $00.00 \% 3$ \\
\hline Oinculty paying household and other buls (excluding mortgagetrent) & 25.00061 \\
\hline Dinculty paying rent of mortgage including arears & $20.0048 \mathrm{~B}$ \\
\hline Creat card deots & $12.50 \mathrm{~m} 5$ \\
\hline Loan debts & $12.50 \% \mathrm{~s}$ \\
\hline Other. please detall any that apply & 10.00004 \\
\hline
\end{tabular}

17 The term 'furlough' refers to staff who were placed on the Government's Coronavirus Job Retention Scheme and had their salary or wage supported by the State. Staff placed on furlough were not allowed to carry out work for their employer, paid or otherwise, while registered on the scheme

${ }^{18}$ Richard Adams, "Coronavirus UK: Universities Face £2.5bn Tuition Fee Loss Next Year,” The Guardian, (2020), http://www.theguardian.com/education/2020/apr/23/ coronavirus-uk-universities-face-25bn-tuition-fee-loss-next-year. 
Table 4

How effective were the Union's internal communications in addressing your financial concerns?

\begin{tabular}{|c|c|}
\hline Field & $\begin{array}{l}\text { Choice } \\
\text { Court }\end{array}$ \\
\hline Extremety effective & $5.250 \mathrm{~m}$ \\
\hline Very effective & $10.53 \%$ \\
\hline Moderately effective & 15.7946 \\
\hline Sughtly eftective & 18.424 \\
\hline Not effective at all & $28.95 \%$ \\
\hline Not sure & 210506 \\
\hline
\end{tabular}

However, where staff did report finance as an issue Table 4 shows that only $15.79 \%$ of participants viewed the unions' internal communications as extremely or very effective in addressing their concerns. Praise for unions largely focused on the issue of pay during furlough:

We were reassured continuously we would continue to receive 100\% pay, even when on furlough.

We received the full 100\% pay during furlough! This was amazing and the Union were great at supporting us with any financial concerns or queries as they told us who to contact if we needed help!

In total, $63.16 \%$ viewed their unions' internal communications as moderately effective or worse in addressing their concerns. Above, it was observed that only $69.23 \%$ of senior managers reported trying to alleviate worries about job security. Whether this was an oversight, or my hypothesis is accurate and managers considered themselves unable to give that reassurance, evidence suggests its absence is feeding into staff anxiety:

Our student union like others are partially dependant on our block grant from the university. If the university lose money... then that is likely to affect their monies coming in. Redundancy packages have been offered to staff in the university... This, at some stage, is likely to affect the block grant of the $S U$.

Even in cases where unions tried to provide reassurances there were occasions where the message failed to get through:

There is reassurance on job security but no evidence behind this, especially as departmental budgets were cut by up to $50 \%$. 
These were issues acknowledged by one senior manager:

The University financial position has shifted quite a bit in recent years though and I think without providing detailed information (evidence if you will) then some staff are probably still not reassured.

The need for unions to address this problem becomes even starker when results are viewed in the context of role and age. Financial problems were far more pronounced for more junior staff. Of the staff who reported anxiety $58.33 \%$ were rank and file employees, $80 \%$ of those having difficulty paying household bills fell into this category as did $50 \%$ of those who struggled to pay their rent or mortgage. A similar picture presents itself in relation to age, 53.33\% of those with anxiety were aged between 25-34 years old and a further 20\% were aged 18-24. When asked how this made them feel, staff made numerous references to stress and anxiety: "stressed me out a lot and kept me up at night"; "caused increased stress, caused upset and anxiety"; "I have had sleepless nights and anxiety attacks". These feelings were perhaps best summarised by one respondent who described the affect as, "emotional only and likely impacted on personal effectiveness and resilience". This encapsulates the human costs and cost to business where staff are operating under these pressures.

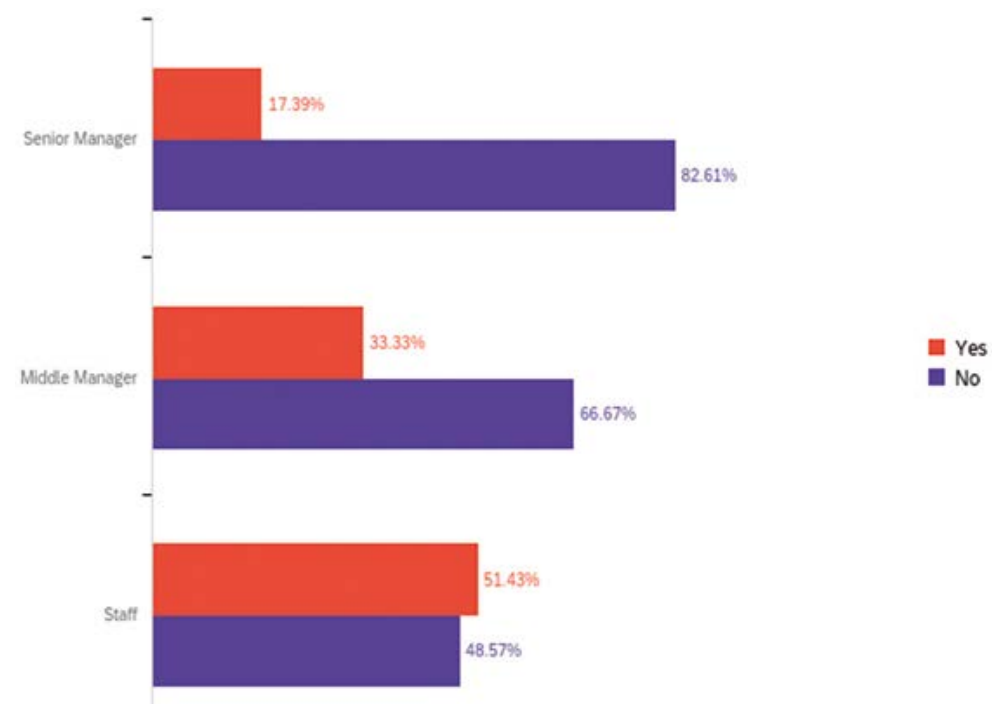

Figure 4

Were you placed on furlough during the pandemic? 
While only $29.58 \%$ of respondents declared financial concerns $65.25 \%$ of respondents said they had feared for their jobs. Given that we are still experiencing the pandemic and appear likely to be for some time yet, this warrants slightly more discussion; because, the longer Covid-19 challenges higher education the greater the likelihood that more union staff will fear for their job and/or experience some form of financial distress. So, what can we learn from furlough?

Figure 4 provides a breakdown of furloughed staff by role designation, showing a predictable distribution based on organisational hierarchies. Table 5 provides an overview of staff who reported that they were worried about their job security during the pandemic. It clearly demonstrates there is a divide between managerial staff and their more junior counterparts.

\section{Table 5}

To what extent have you worried about your personal job security during the pandemic?

\begin{tabular}{|c|c|c|c|c|}
\hline 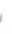 & Fetd & Senior Manoger & Mistile Menager & Statt \\
\hline 1 & To a geat extern & 0.00500 & 200054 & $32.69 \mathrm{~m}+\mathrm{r}-\mathrm{l}$ \\
\hline 2 & To a reasonable extert & $87.5005,7$ & 30.00060 & 442362 \\
\hline 3 & To a Imited extent & $12.50 \% 61$ & $50.00 \% 10$ & $23.00 \% \mathrm{~s}$ \\
\hline & Not sure & 0.00000 & 0.0060 & 0.0050 \\
\hline & & 8 & 20 & 5 \\
\hline
\end{tabular}

The Z-test when considering these concerns in the context of furlough found that $76.5 \%$ of furloughed staff had this concern, compared to just $54.7 \%$ of employees who went un-furloughed. Though interestingly, the Z-test also highlighted that those staff who remained in the workplace were more likely to be concerned about the organisation's viability (64\%) than their furloughed colleagues $(54.9 \%)$ perhaps indicating that while the sense of an immediate personal risk was present for those being furloughed, which took precedence over any wider risk to the organisation, other staff saw this as a sign of what might be to come for them.

While the immediate uncertainty created by being furloughed can be viewed as natural, unions may benefit from reflecting on these findings in terms of how they communicate the need to engage in any similar, future schemes. They should also consider the possibility that as they reintegrate furloughed workers, who may now view themselves as more vulnerable 
during the ensuing financial turmoil, created by Covid-19, than those whose attendance went unbroken.

\section{III.3. Capability}

Table 6 shows a troubling picture of the number of staff who feel less capable in their work than before the pandemic, particularly among those who previously considered themselves the most capable. As can be seen by Table 7, well over a quarter of staff $(29.10 \%)$ also felt their union could have done more to address capability. When asked to provide more details, staff said: "ensured that everyone had the basic capability to do their job through technology and working environment at home"; "communication to check on concerns with technology"; "it took a while for equipment requests to be processed"; "providing access to technology requested a bit sooner"; "provision of equipment earlier than 6 months into the "working from home' approach"; "phone call to discuss our setup, what equipment we require".

\section{Table 6}

Comparison between prior and current sense of capability

\begin{tabular}{|c|c|c|c|c|c|}
\hline " & Fleid & I feet more capable & My capabtity remains the same & I feet less capable & Total \\
\hline so & To a great extent & $11.11 \% 2$ & $77.7896 \quad 14$ & 11.11862 & 18 \\
\hline 51 & To a reasonable extent & $5.8844 \quad 3$ & $56.8695 \quad 29$ & $3725=19$ & 51 \\
\hline 52 & To a limited extent & $15.63 \mathrm{~m} 5$ & $50.004 \quad 16$ & 34.399611 & 32 \\
\hline 53 & To no extent as all & 15.70043 & $31.59 \% 6$ & 52.53510 & 19 \\
\hline 55 & Not sure & 7.14011 & 71.4396 & $21.43 \% \quad 3$ & 14 \\
\hline
\end{tabular}

\section{Table 7}

Do you think your Union could have done more to address capability during the pandemic?

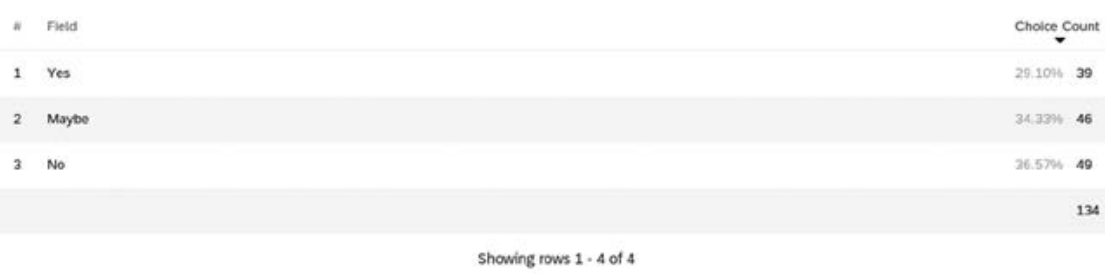


Further evidence of unions' slow response to addressing technology issues can be seen in the Z-tests. Statistical significance can be found between the capability concerns expressed by those staff who were not subject to furlough and those who were. When asked whether their union could have done more to address capability during the pandemic $67.6 \%$ of those who went un-furloughed answered affirmatively, compared to $32.4 \%$ of those who were placed on leave. One possible explanation for this is that by the time furloughed staff were returning to the workplace the majority of these problems had been addressed. Nevertheless, feedback illustrates that in some places this remains a concern "the infrastructure and equipment needed was not addressed until much later and I am still waiting on equipment I have requested.”; “...my access to technology has not been great so my workload is harder to deal with". As these responses clearly demonstrate, unions were slow to respond to the technology needs of their staff and this bred frustrations which it would appear are yet to be fully resolved. A lack of central foresight and oversight appears to have contributed to these problems. Often, departments were left to audit their own technology needs and the competency of individual managers in addressing this was somewhat of a vagary. Numerous staff also commented that they would have found further information on home-working, including on tax relief and health and safety beneficial.

\section{III.4. Belongingness}

\section{III.4.1. Furlough Isolation v. Blitz Spirit}

Bivariate analysis examining the relationship between furlough and the extent to which staff feel a greater, lesser or equal sense of belongingness produces, perhaps unsurprisingly, statistically significant results in relation to the $\mathrm{Z}$ and chi-squared tests. The latter produced a result of $<0.1$, while the former found that staff members who went un-furloughed were more likely to feel a greater sense of belongingness $(18.7 \%)$ than those who were placed on leave $(5.9 \%)$. This may point to a 'blitz spirit' among those left to run services and activities. ${ }^{19}$ It could also be as a result of staff having to cover colleagues' departments in their absence and consequently learning more about the union than they had previously known. Yet, this was in stark contrast to the experience of many furloughed workers whose responses

${ }^{19}$ Blitz spirit refers stoicism and determination in a difficult or dangerous situation. The term derives from the response of Londoners to the Luftwaffe's bombing campaign on the capital between 1940 and 1941 
indicated significant levels of dissatisfaction with the support provided and the impact this had on their sense of belongingness:

Furloughed staff at my Union were effectively stuck in a cupboard and forgotten about... my manager contacted me by email less than once a month for the next five months. Running a few quizzes and inviting people to Teams meetings to find out how well everyone else is coping without them isn't good enough. I felt completely abandoned. No one bothered to check on me, no one asked about my mental health or well-being.

On furlough I felt so lonely and isolated, was never checked in on 1-2-1 by another member of staff. It was highly disappointing.

These issues were recognised by one senior manager who discussed furlough, explaining that it "...made you not want to disturb them too much. In hindsight I think that was a mistake. It led to staff feeling more detached than they needed to".

Furlough may have come to an end, with these staff back in the ranks; however, unions would be well advised to reflect on this data and the experience of their staff, not just in the event that those circumstances change, but also as they reintegrate the $37.3 \%$ of staff who reported a lesser sense of belongingness having been furloughed and where the pandemic may have created a lasting legacy in respect of belongingness.

\section{III.4.2. The clamour for personal contact}

Yet, as Table 8 demonstrates, the concerns were not restricted to those on furlough with $40.7 \%$ of staff believing the Union could have done more to address belongingness. Other, comments from survey respondents illuminate a visceral desire for contact between colleagues, and in particular between line reports and their managers, that is focussed on mental health and general wellbeing. These types of interventions have been perceived as somewhat lacking, as opposed to strictly work-related interactions which participants recognised as being in place. When asked to provide reasoning for their answer, staff said: "more calls for support"; "reaching-out on a personal level"; "setup some non-work related group staff meetings"; "more demand on managers to check-up on staff"; "checking in from senior management at a personal level would have been good"; "daily check-ins to make sure everyone is ok".

A minority of unions appear to have taken explicit action in this area with one manager explaining "we also set up wellbeing checks for each line manager to check with their staff how they are doing”, another explained that 


\section{Table 8}

Do you believe the Union could have done more to address belongingness during the pandemic?

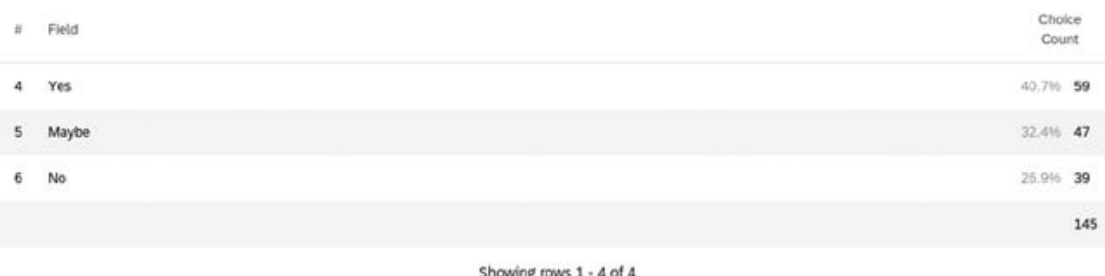

Showing rows 1.4 of 4

a central part of their communications strategy had been "running two wellbeing surveys to compare answers and also compare to the staff survey pre-pandemic". However, these sorts of initiatives were not commonplace across unions, and some senior managers identified this weakness, with one admitting "I also think I should have been in touch with more staff individually".

\section{III.5. Reward and recognition}

Staff exhibiting the lowest levels of pre-pandemic satisfaction with reward and recognition arrangements were the most likely to view there as being less available since the onset of Covid-19 (44.44.\%). Similarly, $40.77 \%$ of respondents considered their union had the potential to do more in this area and, as Table 9 demonstrates, only $8.46 \%$ of staff felt their union's communications dealt with reward and recognition to a great extent during the pandemic whereas over $15.38 \%$ felt had not been covered at all.

\section{Table 9}

To what extent do you think the Union's internal communications have addressed reward and recognition?

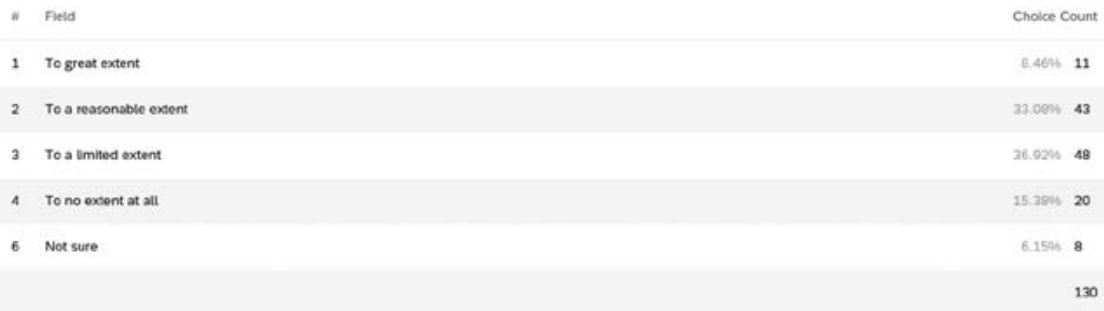

Showing rows 1.6 of 6 
When staff were asked to explain what more could have been, done distinct themes relating to reward and recognition emerged. In terms of reward some staff felt small gestures would have been welcomed: "thank you cards in the post or small, inexpensive care packages might have had a really big impact,particularly for colleagues who lived alone"; "appreciation/ thank you cards would have been a nice gesture”.

However, recognition seemed to be the bigger concern for staff. Evidence suggests that the move to forced home-working has exacerbated a feeling among staff that 'silos' are in operation across unions. A major consequence of this includes obscured lines of sight to colleagues' good work. As one staff member put it:

I think communication between teams has been the major downfall at our Union and it feels like it has become more siloed again, something that we had been successful at changing over the last few years prior to COVID.

Other staff made similar comments: "cross-department communication has suffered quite a lot"; "they [the union] could have made greater attempts to keep us connected to other departments"; "more collaboration between departments for virtual activities would have made us feel more like a single organisation". A palpable sense can be seen emerging that this is restricting recognition: "if someone achieved something... then it should have been made known to all departments"; "much of our recognition assumes staff will be in the building... we didn't come up with a plan to separate that".

These views are reinforced by Figure 5 which shows the limited number of staff who felt internal communications tackled reward and recognition to a great extent. Especially interesting are the Z-test results for the number of middle managers $(20 \%)$ who felt that internal communications addressed reward and recognition to no extent at all. The fact that middle managers are significantly more likely than their colleagues to view reward and recognition as being absent from communications might say something about how this group feel they have been treated. A possible explanation for this is that middle managers were furloughed later than their line reports, particularly as part-time furlough became available, and feel that their efforts to 'hold down' departments with limited staff resource have not been fully, or at least explicitly, appreciated by senior staff.

Unions may benefit from reflecting on whether they have suitable reward and recognition arrangements in place for hybrid provision and whether more can be done to encourage collaboration across the union and in 

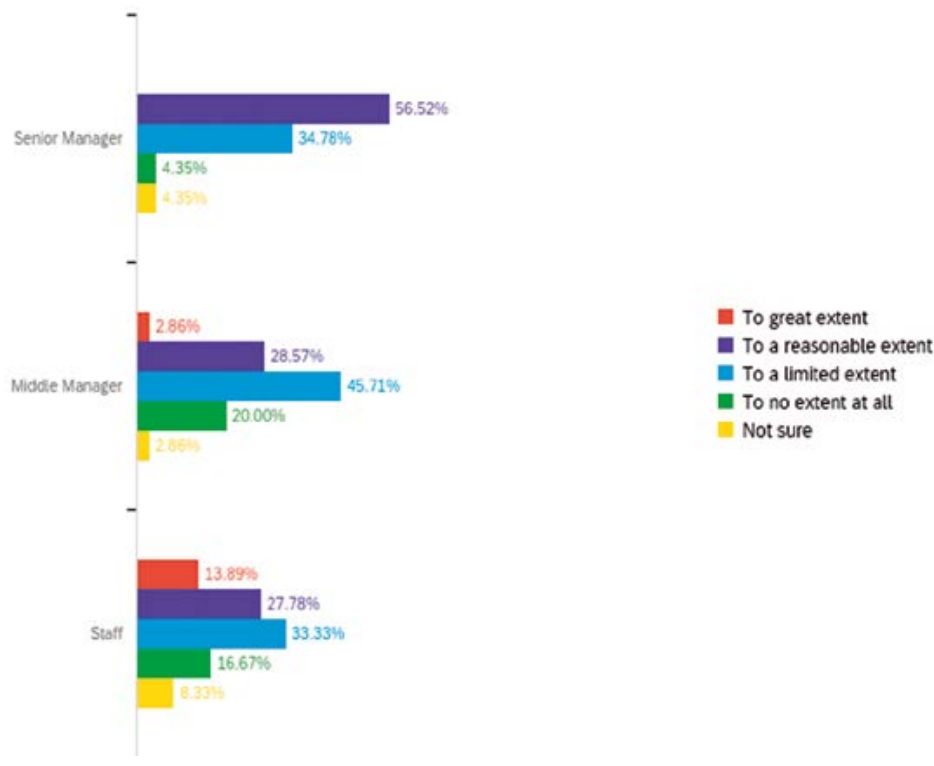

Figure 5

To what extent have the Union's internal communications addressed reward and recognition?

particular recognise the contribution middle managers are making to managing their departments through turbulent times. As one middle manager put it, "Very little mention of good work or recognition from senior management. No rewards at all".

\section{III.6. Career support and professional development opportunities}

Overall, respondents had much less to say about career support and professional development opportunities, in comparison to the other factors covered under the survey. This may well reflect the fact that they view their major concerns in this area pre-date Covid-19 and have not been greatly affected by it. Table 10 shows that, when asked whether the union provided sufficient career support and CPD opportunities, over $30 \%$ of staff felt this was done to a limited extent or to no extent all. In total, $42.06 \%$ staff feel that there is less support in place since the start of the pandemic and $52.8 \%$ of staff though it might have been possible for their union to have done more. 
Table 10

To what extent do you think the Union provided sufficient career support and professional development opportunities prior to Covid-19?

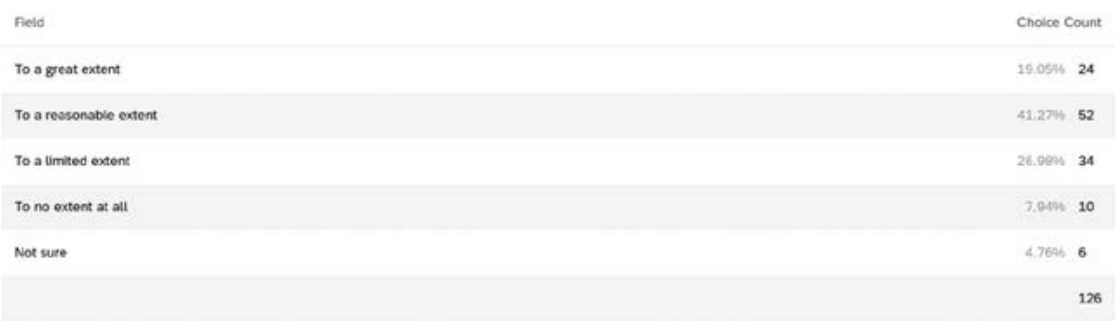

Showing rows 1.6 of 6

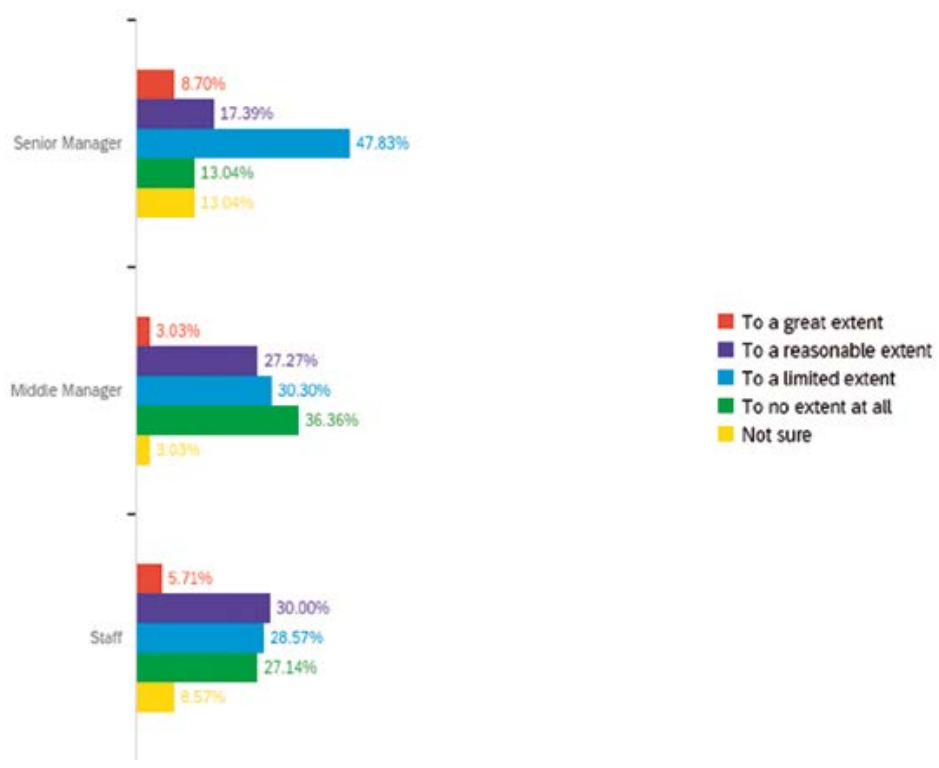

Figure 6

To what extent have the Union's internal communications addressed career support and development opportunities?

Instinctively, and especially given the data and prominent media coverage concerning the disproportionate impact of pandemic is having on the employment and career prospects of young people, it could be predicted that 
the youngest staff are most likely to be concerned about career support and development opportunities. While $39.1 \%$ of those aged 18-35 reported concern it was actually those aged 25-34 who were most troubled (53.8\%). When you consider this in the context of Figure 6, one possible explanation is that it is actually young middle managers who are most concerned, those who were unhappy with the existing provision and are now becoming increasingly concerned about what they see as evaporating opportunities for advancement. Certainly, these comments from middle managers would support that theory:

There hasn't been any communication about whether personal development opportunities will still be available in the coming academic year... but it would be good to have a firm central stance especially for managers.

The Union needs to do more regardless of Covid. It is happy to accept that we are a 'flat organisation' and therefore development opportunities are limited. This is a short-sighted approach.

\section{Conclusion}

This evaluation sought to answer what Mayne terms 'managerial' questions, about whether it was reasonable to conclude that the programme (internal communications) had made a difference to the problem (staff motivation). In addressing this, I was seeking to contribute to the students' union sector's learning and understanding; in particular; surrounding what more can be done to enhance staff motivation during subsequent phases of the pandemic.

So, what kind of contribution claim can be made based on the evaluation? I would argue that my work represents a contribution analysis of direct influence. ${ }^{20}$ The quantitative data presented outlines the trajectory of staff motivation, in the areas set out through the theory of change, before and during the pandemic. The influence that internal communications has had in affecting that trajectory, positively or negatively, is substantiated not just by the quantitative data alone but also by the rich qualitative feedback solicited from participants. For example, some staff reporting reduced belongingness are unhappy at what they perceive as the lack of personalised contact, in

${ }^{20}$ John Mayne, "Contribution Analysis: An Approach to Exploring Cause and Effect," (2008), https://www.betterevaluation.org/sites/default/files/ILAC_Brief16_Contribution_ Analysis.pdf. 
particular from line managers. Consider this in the context of the theory of change, and the risks it incorporated, and you realise that inappropriate communications were used, and this has had a negative impact on motivation. Conversely, communications have been effective where staff were anxious about financial concerns due to job security and pay and the Union has alleviated these by providing clear information on furlough and the union's financial position. However, this could have been enhanced for some staff by providing additional information (in this case that could have included financial accounts) where they felt that communications lacked sufficient evidence. Further examples of this direct influence are present throughout my findings.

In terms of the evaluation's contribution to knowledge and potential lessons for unions, it demonstrates there has been insufficient granularity in unions' communications strategies during the pandemic and, while there is no 'silver bullet' when it comes to developing strategies for addressing staff motivation, unions could and should take greater account of individuals' preferences, including when it comes to communications. My findings provide new knowledge in this area (for instance around the experience of furloughed workers) and offer one potential resource for unions to help them achieve a deeper understanding of the experience of their staff.

\section{Limitations and future directions}

On reflection I would have introduced an additional survey area based on Maslow's 'safety' tier. This would have focussed on staff concerns surrounding their health and the health of their families. Despite this, respondents had the opportunity to reference other personal concerns during the pandemic and only one individual cited such concerns. This perhaps indicates that it was not a preeminent concern for students' union staff (possibly because of the relatively young age profile), and/or that they did not feel their union was able to address their concerns in this area.

Demographic data did not focus on gender, instead concentrating on income, age and ethnicity. Given the disproportionate impact the pandemic is known to have had on Black, Asian and Minority Ethic (BAME), lower income and older individuals these were and remain appropriate variables for analysis. However, following the fieldwork period, reports variously suggested that women aged twenty to forty were being disproportionately hospitalised during the early part of the 'second wave', that pregnant women have heightened risks and that the economic consequences of the pandemic will be felt most acutely by women. Consequently, greater emphasis would be given 
to the effects on female respondents in any repeat study. Additionally, $89 \%$ of respondents were white, making it hard to draw any significant conclusions about the experience of BAME staff. Again, the paucity of national data is a problem here but recent work from the NUS suggests only $14 \%$ of union staff are from a minority. ${ }^{21}$ Therefore, interviews or focus groups may provide a more effective route to producing robust findings for this group of staff.

Based on the data collected during this evaluation I would also adjust my theory of change. At the communication stage I think the risks need to be expanded to include 'incomplete communications'. Currently, the risks do not take into account the fact that managers could devise suitable interventions but then not communicate them in their entirety to staff.

As referenced earlier, five unions requested detailed data reports to support organisational planning. This introduces a strong practical utility in relation to the evaluation's findings. However, it also raises the prospect of a further study, exploring unions' use of the evaluation outcomes, this could include additional qualitative elements with senior staff, middle managers and staff to understand how the evaluation led to the adaptation of practices and whether these changes have also influenced motivation.

\section{Bibliography}

Adams, Richard. "Coronavirus UK: Universities Face $£ 2.5$ bn Tuition Fee Loss Next Year." The Guardian, April 23, 2020. http://www.theguardian.com/education/2020/ apr/23/coronavirus-uk-universities-face-25bn-tuition-fee-loss-next-year.

Costa Dias, Monica. Robert Joyce and Agnes Norris Keiller. "Covid-19 and the Career Prospects of Young People,” Institute for Fiscal Studies, July 3, 2020. https://www.ifs.org.uk/publications/14914.

Day, Mike, and Jim Dickinson. "David Versus Goliath: The Past, Present and Future of Students' Unions in the UK," Higher Education Policy Institute (2018). https://www.hepi.ac.uk/2018/09/06/david-versus-goliath-past-present-futurestudents-unions-uk/.

Gillespie, Tom. "Coronavirus: Students Say Starting University During the Pandemic Is Impacting Their Mental Health,” Sky News, September 26, 2020. https://news. sky.com/story/coronavirus-students-say-starting-university-during-thepandemic-is-impacting-their-mental-health-12081273.

Johanson, Mark. "Hybrid Work: What the Office Could Look Like Now," $B B C$, July 14, 2021. https://www.bbc.com/worklife/article/20210713-hybrid-work-whatthe-office-could-look-like-now.

${ }^{21}$ NUS, “SU Employee Engagement Fast Facts,” National Union of Students, (2018) https://www.nusconnect.org.uk/nus-insight/myguide/student-union-data/su-employeeengagement-fast-facts. 
King, David. "Independent Sage Response to Sage "Principles for Managing SarsCov-2 Transmission Associated with Higher Education"," Independent SAGE, September 9,2020. https://www.independentsage.org/wp-content/uploads/2020/ 09/iSAGE-response-to-SAGE-HE-FINAL-09-09-2020.pdf.

Maslow, A. H. "A Theory of Human Motivation." Psychological Review 50, no. 4 (1943): 370-96.

Mayne, John. "Contribution Analysis: An Approach to Exploring Cause and Effect," BetterEvaluation, (2008) https://www.betterevaluation.org/sites/default/files/ ILAC_Brief16_Contribution_Analysis.pdf.

“Contribution Analysis: Coming of Age?". Evaluation 18, no. 3 (2012): 270-80.

Mullins, Laurie J. Management and Organisational Behaviour. Welwyn Garden City, UNITED KINGDOM: Pearson Education UK, 2013.

NUS. "SU Employee Engagement Fast Facts," National Union of Students, 2018. https://www.nusconnect.org.uk/nus-insight/myguide/student-union-data/suemployee-engagement-fast-facts.

Onanuga, Tola. “The Government's Disastrous a-Level Scandal Reveals Its Contempt for the Working Class," Prospect Magazine, August 20, 2020. https://www. prospectmagazine.co.uk/politics/government-a-levels-grades-uk-explaineddowngraded-gavin-williamson-algorithm-btec.

Partington, Richard. "Economic Fallout from Pandemic Will Hit Women Hardest," The Guardian, July 24, 2020. http://www.theguardian.com/world/2020/jul/24/ economic-fallout-from-pandemic-will-hit-women-hardest.

QAA. "How UK Higher Education Providers Managed the Shift to Digital Delivery During the Covid-19 Pandemic," The Quality Assurance Agency, 2020. https:// www.qaa.ac.uk/docs/qaa/guidance/how-uk-higher-education-providersmanaged-the-shift-to-digital-delivery-during-the-covid-19-pandemic.pdf.

Sample, Ian. "Younger Women 'Bearing Brunt' of Second Wave of Covid in UK," The Guardian, September 22, 2020. http://www.theguardian.com/world/2020/ sep/22/younger-women-bearing-brunt-of-second-wave-of-covid-in-uk.

Smith, Lyn. Part 1: Setting the Scene - Chapter 04: Theories into Practice 2nd ed. ed. London: Kogan Page Ltd, 2008.

UCU. "Universities Must Not Become the Care Homes of a Covid Second Wave," University College Union, August 29,2020. https://www .ucu.org.uk/article/10964/ Universities-must-not-become-the-care-homes-of-a-Covid-second-wave.

\section{About the author}

MATTHEW KITCHING (m.kitching1@lancaster.ac.uk) is Deputy Chief Executive Officer of the Students' Union at Buckinghamshire New University (United Kingdom, UK). Simultaneously, Matthew is completing his MBA in the Edinburgh Business School at Heriot-Watt University and undertaking his $\mathrm{PhD}$ in Higher Education at Lancaster University (UK). As part of the latter, his research focusses on projects concerning student unions, student leadership and engagement, as well as work on quality assurance, in particular student 
involvement in international QA. Matthew also works for a wide range of quality assurance agencies across Europe and previously worked for the European Students' Union. He is also a Board member of EQ-Arts and the European Council for Business Education. In addition, Matthew is Regional Editor (Western Europe) of the Journal of Comparative \& International Higher Education, a peer reviewer for the Student Engagement in Higher Education Journal and a member of the Society for Research into Higher Education, the Consortium of Higher Education Researchers and the National Association of Student Personnel Administrators, where he holds the position of Graduate Student Co-Chair of the International Education Knowledge Community. 


\title{
A mixed methods contribution analysis of UK students' unions' internal communications response to addressing staff motivation during the Covid-19 pandemic
}

\author{
Matthew Kitching
}

doi: http://dx.doi.org/10.18543/tjhe-9(1)-2021pp207-237

\section{Copyright}

Copyright for this article is retained by the Publisher. It is an Open Access material that is free for full online access, download, storage, distribution, and or reuse in any medium only for noncommercial purposes and in compliance with any applicable copyright legislation, without prior permission from the Publisher or the author(s). In any case, proper acknowledgement of the original publication source must be made and any changes to the original work must be indicated clearly and in a manner that does not suggest the author's and or Publisher's endorsement whatsoever. Any other use of its content in any medium or format, now known or developed in the future, requires prior written permission of the copyright holder. 